\title{
Cervico-isthmic pregnancy developing within the scar of a previous cesarean section: a case report
}

\author{
Achille Tolino • Lucia Battista • Gaetano Chiacchio • \\ Erika Rania • Caterina Materazzo • Stefano Palomba
}

Received: 19 May 2009 / Accepted: 13 August 2009/Published online: 23 September 2009

(C) Springer-Verlag 2009

\begin{abstract}
The cervico-isthmic pregnancy is a rare event occurring during pregnancy. In this current report, we describe a case of a woman with pregnancy developed within a previous cesarean section scar and successfully treated with conservative management.
\end{abstract}

Keywords Cesarean section scar · Ectopic pregnancy Laparoscopy · Laparotomy · Surgery · Ultrasonography

\section{Introduction}

The cervico-isthmic pregnancy has an incidence of $1: 1,800-1: 2,200$ of pregnancies $[1,2]$, even though its true incidence is unknown because of the few cases reported in literature [3].

Among the ectopic pregnancies, those developing within the scar of a previous cesarean section are considered the rarest kind of ectopic pregnancy, even representing a lifethreatening condition [3]. In fact, it is related with a lot of complications, such as spontaneous miscarriage in the first or second trimester of pregnancy or preterm partum $[4,5]$, uterine rupture, massive hemorrhage, hysterectomy, and maternal mortality [6]. Herman et al. [4] reported a case of pregnancy implanted on previous cesarean section, which

A. Tolino $\cdot$ L. Battista $\cdot$ G. Chiacchio Departments of Obstetrics and Gynecology, University "Federico II" of Naples,

Naples, Italy

E. Rania $\cdot$ C. Materazzo $\cdot$ S. Palomba $(\square)$ Department of Gynecology and Obstetrics, University "Magna Graecia" of Catanzaro-Viale Europa, 88100 Catanzaro, Italy

e-mail: stefanopalomba@tin.it carried to a hysterectomy because of the development of a profound hemorrhage and disseminated intravascular coagulopathy. All these conditions can lead inevitably to fertility loss and to long-term side effects, which decrease the quality of life [7]. In this current report, we describe a case of a woman with isthmic pregnancy developed in a cesarean section scar and successfully treated with conservative management despite an initial erroneous diagnosis of cervical pregnancy.

\section{Case report}

A 35-year-old woman, gravida 2, with a previous cesarean section for eclampsia in 2003, was admitted to our department for cervical pregnancy at 6 weeks and 1 day of gestation. At the admission, the blood count was red cell $4.95 \times 10^{6} / \mu \mathrm{L}$, hemoglobin $(\mathrm{Hb}) 13.60 \mathrm{~g} / \mathrm{dl}$, and white cell $6.46 \times 10^{3} / \mu \mathrm{L}$. The patient underwent to transvaginal ultrasound that showed a retroverse enlarged uterus and a gestational sac with a single $3 \mathrm{~mm}$ embryo with heart activity at the level of the cervical canal. Adnexals were normal. An intramural posterior myoma of $1.2 \mathrm{~cm}$ was detected (Fig. 1).

Since the patient's clinical condition was stable, we started a medical therapy with intramuscular methotrexate (50 mg daily). After one day, a little vaginal bleeding was present. The blood count resulted as follows-red cell $4.38 \times 10^{6} / \mu \mathrm{L}, \mathrm{Hb} 12.80 \mathrm{~g} / \mathrm{dl}$, and white cell $7.60 \times 10^{3} / \mu \mathrm{L}$. The patient was treated with five methotrexate injections spaced out with a daily intramuscular injection of folate. In the last day of treatment, the woman underwent a further abdominal ultrasound examination that evidenced the cervix laterally displaced on the left, cervical flexion angle extremely emphasized, and the uterine corpus extremely 

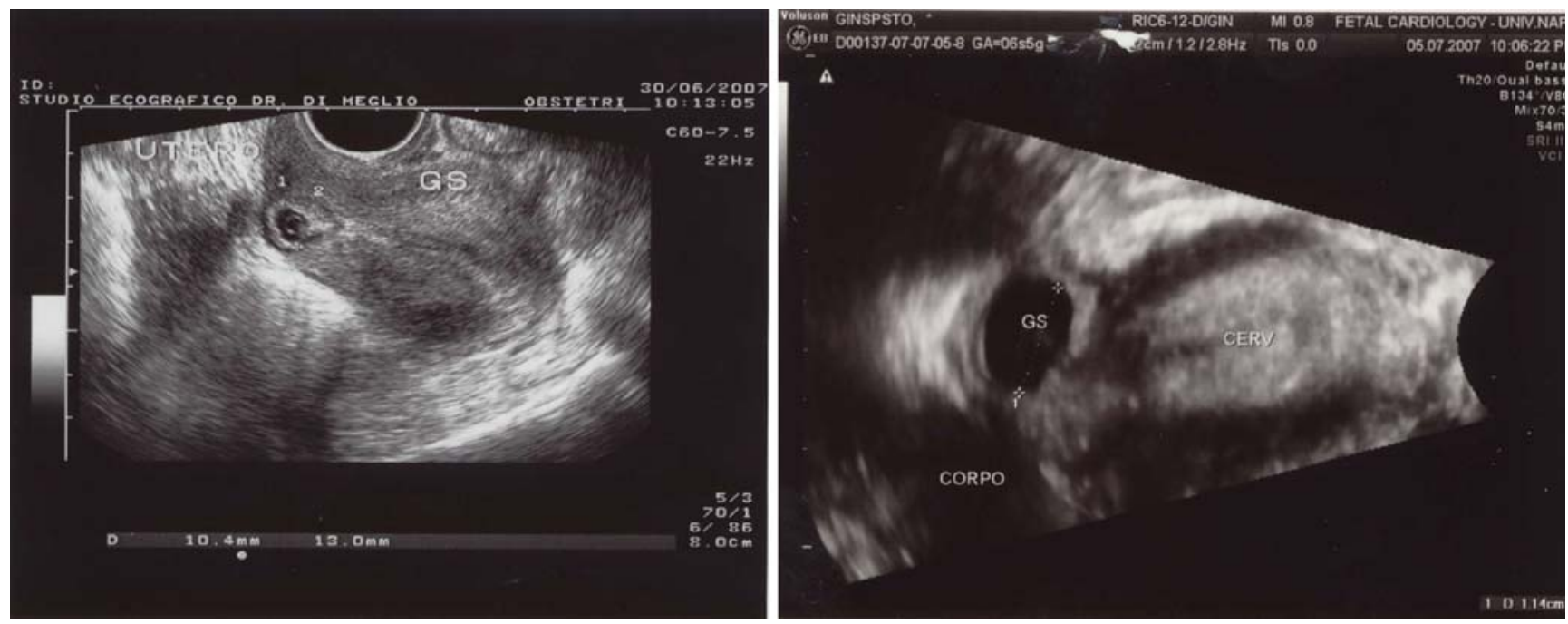

Fig. 1 Ultrasonographic scans showing the gestational sac located in deep myometrium at cervico-isthmic level

retroversed in the Douglas. Transvaginal ultrasound showed in anterior uterine wall and, specifically, at cervico-isthmic level a gestational sac of $15 \mathrm{~mm}$ located in deep myometrium with a live embryo. The localization of the ectopic pregnancy resulted on the previous cesarean scar. According to crown-rump length, the gestational age resulted of 7 weeks. The gestational sac was surrounded by a hyperechogenic halo, probably, due to trophoblastic tissue.

In order to avoid a uterine rupture, a surgical intervention was suggested to the woman. A detailed informed consent about the potential risks and complications of a surgical treatment due to this condition was presented to the patient. The woman preferred to undergo to laparotomy to reduce the operative time and to avoid the risk of conversion.

Laparotomy started with a transversal skin incision on the previous laparotomic scar. The abdominal wall was open in layers. The uterus was retroverse-flected, and the bladder was deformed because of a tumefaction of $3 \mathrm{~cm}$, which developed from uterine isthmus. A cervico-isthmic pregnancy infiltrating completely the myometrium and contracting adhesions with posterior wall of the bladder was confirmed (Fig. 2). The bladder was separated with scissors from the mass just above it, and the ectopic pregnancy was excised using a monopolar needle (Fig. 3). The intracavitary decidual tissue was removed by suctioning. The cervico-isthmic area was repaired in double layers arranging the uterine breach longitudinally. The bladder was completely mobilized from lower portion of the uterus and repaired in single layer (Fig. 4). The integrity of the bladder was then tested with instillation of methylene blue dye.

No postoperative complication was reported, and the patient was discharged 5 days after surgery. After 1 year from surgery, the patient's condition was good. For personal choice, no further attempt to achieve a new pregnancy was made.

\section{Discussion}

As suggested by Vial et al. [8], the cervico-isthmic pregnancy can lead to live birth. In fact, it can be characterized by a progression that occurs towards the cervico-isthmic space or through the uterine cavity. In this last case, the connection to the cavum uteri could lead pregnancy progress to a viable birth [4]. This issue is the rationale of the choice of an expectant management [9].

Even if the expectant treatment can be a valid option, it is often associated with an emergency hysterectomy [10] due to postpartum massive bleeding. In the cervico-isthmic

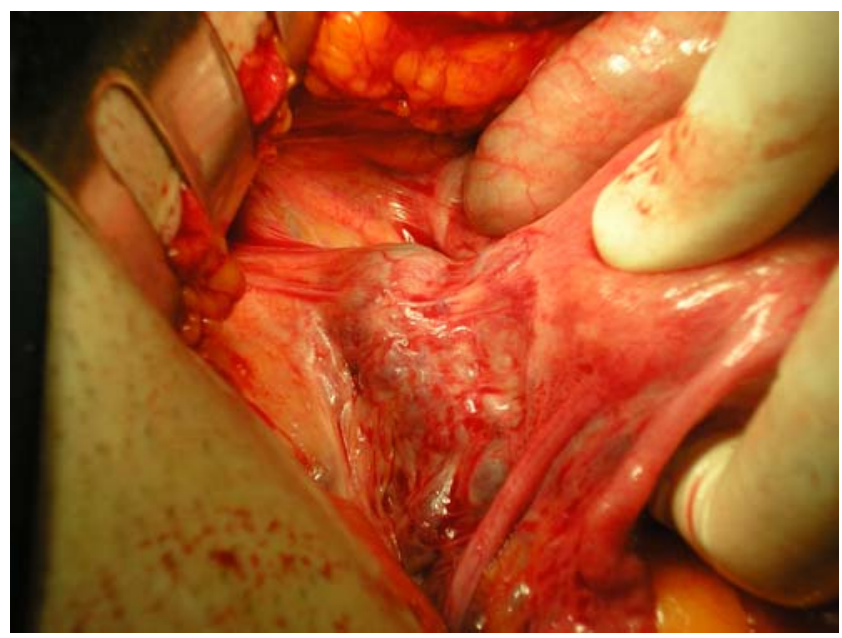

Fig. 2 Cervico-isthmic pregnancy infiltrating completely the myometrium and contracting adhesions with posterior wall of the bladder 


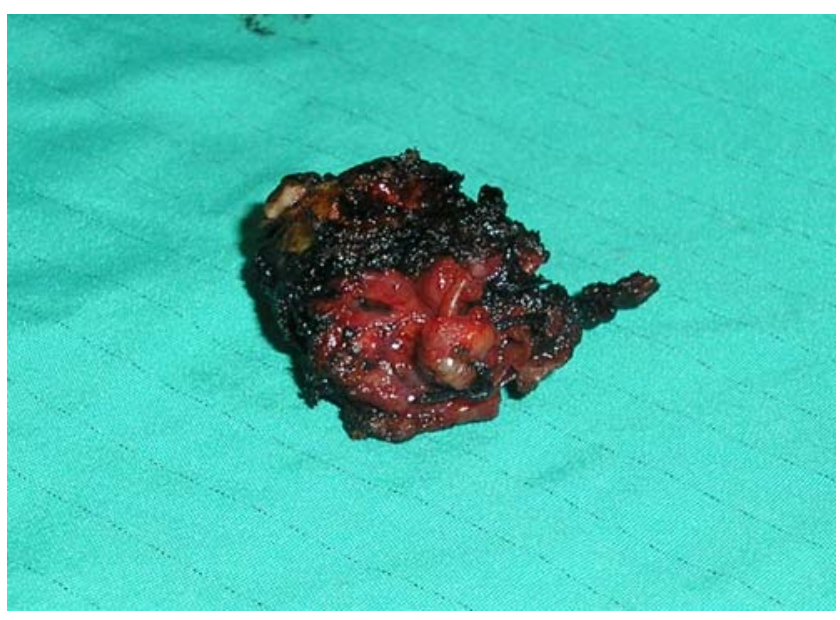

Fig. 3 Ectopic pregnancy excised using a monopolar needle

implant, the gestational sac is located between cervix, distally, and the decidualized functional endometrium, cranially [10]. A weakness of the cervical canal plays a role in the pathogenesis of cervico-isthmic pregnancy [10].

Pregnancy on previous cesarean scar is the rarest form of ectopic pregnancy, and a lot of theories have been suggested to explain its pathogenesis $[3,11-13]$. Recently, the rate of cervico-isthmic pregnancy is increased because of enhancement of the in vitro fertilization, embryo transfer, microsurgical techniques, or better and/or early diagnosis [14], even if the most frequent cause of cervico-isthmic pregnancy is the spreading use of cesarean section [15]. For this reason, gynecologists must always suspect the possibility of a cervico-isthmic pregnancy in women with a previous cesarean section scar [6]. The diagnosis of pregnancy on cesarean scar is easily made by transvaginal ultrasound and color Doppler flux, which allow the determination of its localization, age, size, and viability [16]. The magnetic resonance imaging can be used to confirm the diagnosis [14].

Unfortunately, in some cases, as well as in the current, the diagnosis cannot be simple. In fact, when the gestational sac is located in the lower part of the uterine cavity, it became difficult to differentiate from a spontaneous miscarriage, a cervical pregnancy, or a cesarean scar pregnancy [13]. The criteria, which should be present to diagnose the cervico-isthmic pregnancy, are as follows: (a) empty uterine cavity and cervical canal; (b) development of gestational sac in the anterior uterine wall at the isthmus (site of the previous cesarean section scar); (c) evidence of functional trophoblastic circulation at Doppler examination, defined by the presence of an area of increased peritrophoblastic vascularity at this examination [1]; (d) absence of healthy myometrium between the bladder and sac [17]; (e) demonstration of a discontinuity at level of the anterior wall of the uterus (on sagittal plane, when ultrasound rounds through the amniotic sac) $[8,13]$.
To date, there is not a standard treatment for this kind of ectopic pregnancy due to the rarity of this condition. In case of isthmic pregnancy, the treatment of choice is the interruption of pregnancy in the first trimester of gestation [18]. Several management options have been proposed to terminate pregnancy and to preserve the uterus [16]. The two main treatment options are a surgical approach or a medical one.

Larsen and Salomon [19] firstly reported a case of a pregnancy implanted on cesarean scar, and they used laparotomy to remove gestational sac. Godin et al. [17] suggested an injection of potassium chloride in the fetal thorax and local methotrexate in the gestational sac or systemic methotrexate injection. Nawroth et al. [20] also described the effect of local and systemic methotrexate administration.

The use of dilatation and curettage has been also described as treatment for cesarean scar pregnancy when the area of the gestational tissue is misdiagnosed [19, 21]. Furthermore, other authors [22] suggested that dilatation and curettage is contraindicated for this kind of ectopic pregnancy, since they are considered as cause of uterine perforation and intractable bleeding and consequently, hysterectomy.

Valley et al. [23] suggested a minilaparotomy incision in order to remove the gestational tissue complicated by hemorrhage during hysterectomy. Yang et al. [24] proposed a conservative treatment followed by a transarterial embolization of bilateral uterine arteries, performed to avoid intraoperative hemorrhage and postoperative bleeding. This technique preserves uterus and reduces the morbidity [24]. Arslan et al. [25] for a pregnancy on previous cesarean scar performed a suction curettage with Karman cannules under transabdominal ultrasonographic guidance and suggested

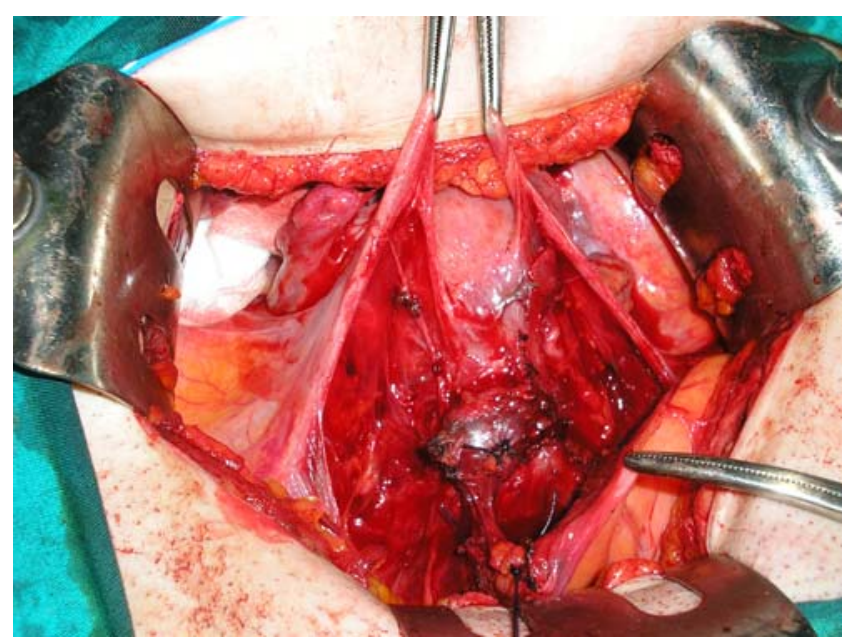

Fig. 4 Cervico-isthmic area repaired in double layers arranging the uterine breach longitudinally and bladder completely mobilized from lower portion of the uterus and repaired in single layer 
that this technique can be used in selected cases (early diagnosed, without symptoms that necessitate emergency intervention).

An early diagnosis of cesarean scar pregnancy consents to undertake a conservative treatment [26]. If the pregnant reported no clinical evidence of suffering, such us bleeding or abdominal pain, and the diagnosis is made at an early stage, we can consider a conservative management with systemic or local injection of methotrexate, potassium chloride, and hyperosmolar glucose [17, 21, 27-29]. However, recent reports evidenced that the cases treated with local or systemic methotrexate, often required laparotomy due to massive hemorrhage [30]. Lee et al. [31], in a retrospective review, enlisted nine women diagnosed with ectopic pregnancy on previous cesarean section scar; seven of them underwent laparoscopic treatment, thus, the gestational sac was removed by laparoscopy without converting to laparotomy, and the scar defect was repaired by intracorporeal sutures. Therefore, the laparoscopic management of pregnancy implanted on previous cesarean scar could be considered the gold standard treatment. In fact, laparoscopy allows removal of the gestational sac and to repair the scar's defect, preserving the uterus and the fertility.

In our case, the patient, at first, underwent to conservative treatment with intramuscular methotrexate injections. Then, after 5 days of management, the transvaginal ultrasound still showed a gestational sac with $15 \mathrm{~mm}$ live embryo. Thus, the patient underwent to laparotomic removal of cesarean scar pregnancy to avoid or to minimize the risks and the complications. Fortunately, in this case, the abdominal treatment was effective and safe. A laparoscopic approach was also proposed to the woman, but she was clearly informed on the paucity of scientific data at regard and on the potentially high complexity of the procedure. Thus, she chose the traditional approach with abdominal transverse incision.

In conclusion, an early diagnosis and an immediate management of pregnancy implanted on previous cesarean scar are necessary to avoid the severe complication of this kind of ectopic pregnancy and to preserve the woman's fertility and the possibility of future pregnancies. Even if the rarity of this clinical event pays the forfeit of the absence of a standardized treatment, a conservative approach should be always attempted.

Conflicts of interest There is no actual or potential conflict of interest in relation to this article.

\section{References}

1. Jurkovic D, Hillaby K, Woelfer B, Lawrence A, Salim R, Elson CJ (2003) First-trimester diagnosis and management of pregnan- cies implanted into the lower uterine segment Cesarean section scar. Ultrasound Obstet Gynecol 21:220-227

2. Seow KM, Huang LW, Lin YH, Lin MY, Tsai YL, Hwang JL (2004) Cesarean scar pregnancy: issues in management. Ultrasound Obstet Gynecol 23:247-253

3. Fylstra DL, Pound-Chang T, Miller MG, Cooper A, Miller KM (2002) Ectopic pregnancy within a Caesarian delivery scar: a case report. Am J Obstet Gynecol 187:302-304

4. Herman A, Weinraub Z, Avrech O (1995) Follow up and outcome of isthmic pregnancy located in a previous caesarean section scar. Br J Obstet Gynaecol 102:839-841

5. Donald F (2002) Ectopic pregnancy within a cesarean scar: a review. Obstet Gynecol Surv 57:537-543

6. Iyibozkurt AC, Topuz S, Gungor F, Kalelioglu IH, Cigerli E, Akhan SE (2008) Conservative treatment of an early ectopic pregnancy in a cesarean scar with systemic methotrexate-case report. Clin Exp Obstet Gynecol 35:73-75

7. Ben Nagi J, Helmy S, Ofili-Yebovi D, Yazbek J, Sawyer E, Jurkovic D (2007) Reproductive outcomes of women with a previous history of Caesarean scar ectopic pregnancies. Hum Reprod 22:2012-2015

8. Vial Y, Petignat P, Hohlfeld P (2000) Pregnancy in a cesarean scar. Ultrasound Obstet Gynecol 16:592-593

9. Ghezzi F, Lagana D, Franchi M, Fugazzola C, Bolis P (2002) Conservative treatment by chemotherapy and uterine arteries embolization of a Caesarian scar pregnancy. Eur J Obstet Gynecol Reprod Biol 103:88-91

10. Strobelt N, Locatelli A, Ratti M, Ghidini A (2001) Cervicoisthmic pregnancy: a case report, critical reappraisal of the diagnostic criteria, and reassessment of the outcome. Acta Obstet Gynecol Scand 80:586-588

11. Scaletta T, Kaplan BC (1994) Ectopic pregnancy. N Engl J Med 330:713-714

12. Van de Meerssche M, Verdonk P, Jacquemyn Y et al (1995) Cervical pregnancy: three case reports and review of literature. Hum Reprod 10:1050-1055

13. Tan G, Chong YS, Biswas A (2005) Caesarean scar pregnancy: a diagnosis to consider carefully in patients with risk factors. Ann Acad Med Singapore 34:216-219

14. Dialani V, Levine D (2004) Ectopic pregnancy: a review. Ultrasound Q 20:105-117

15. Chang CY, Wu MT, Shih JC, Lee CN (2006) Preservation of uterine integrity via transarterial embolization under postoperative massive vaginal bleeding due to cesarean scar pregnancy. Taiwan J Obstet Gynecol 45:183-187

16. Haimov-Kochman R, Sciaky-Tamir Y, Yanai N, Yagel S (2002) Conservative management of two ectopic pregnancies implanted in previous uterine scars. Ultrasound Obstet Gynecol 19:616-619

17. Godin PA, Bassil S, Donnez J (1997) An ectopic pregnancy developing in a previous caesarean section scar. Fertil Steril 67:398-400

18. Ash A, Smith A, Maxwell D (2007) Caesarean scar pregnancy. BJOG 114:253-263

19. Larsen JV, Solomon MH (1978) Pregnancy in a uterine scar sacculus. An unusual cause of post abortal haemorrhage. South Afr Med J 53:142-143

20. Nawroth F, Foth D, Wilhelm L, Schmidt T, Warm M, Romer T (2001) Conservative treatment of ectopic pregnancy in a caesarean section scar with methotrexate: a case report. Eur J Obstet Gynecol Reprod Biol 99:135-137

21. Seow KM, Cheng WC, Chuang J, Lee C, Tsai YL, Hwang JL (2000) Methotrexate for cesarean scar pregnancy after in vitro fertilization and embryo transfer- a case report. J Reprod Med 45:754

22. Lee CL, Wang CJ, Chao A, Yen CF, Soong JK (1999) Case report: laparoscopic management of an ectopic pregnancy in a previous Caesarean section scar. Hum Reprod 14:1234-1236 
23. Valley MT, Pierce JG, Daniel TB, Kaunitz AM (1998) Cesarean scar pregnancy: imaging and treatment with conservative surgery. Obstet Gynecol 91:838-840

24. Yang MJ, Jeng MH (2003) Combination of transarterial embolization of uterine arteries and conservative surgical treatment for pregnancy in a cesarean section scar: a report of three cases. J Reprod Med 48:213-216

25. Arslan M, Pata O, Dilek TU, Aktas A, Aban M, Dilek S (2005) Treatment of viable cesarean scar ectopic pregnancy with suction curettage. Int J Gynaecol Obstet 89:163-166

26. Pascual MA, Hereter L, Graupera B, Tresserra F, Fernandez-Cid M, Simon M (2007) Three-dimensional power Doppler ultrasound diagnosis and conservative treatment of ectopic pregnancy in a cesarean section scar. Fertil Steril 88(706):e5-e7

27. Ravhon A, Ben-Chetrit A, Rabinowitz R, Neuman M, Beller U (1997) Successful methotrexate treatment of a viable pregnancy with a thin uterine scar. Br J Obstet Gynecol 104:628-629
28. Roberts H, Kohlenber C, Lanzarone V, Murray H (1998) Ectopic pregnancy in lower segment uterine scar. Aust NZ J Obstet Gynecol 38:114-116

29. Shufaro Y, Nadjari M (2001) Implantation of gestational sac in a Caesarian section scar. Fertil Steril 75:1217

30. Sugawara J, Senoo M, Chisaka H, Yaegashi N, Okamura K (2005) Successful conservative treatment of a cesarean scar pregnancy with uterine artery embolization. Tohoku J Exp Med 206:261265

31. Lee JH, Kim SH, Cho SH, Kim SR (2008) Laparoscopic surgery of ectopic gestational sac implanted in the cesarean section scar Surg Laparosc Endosc Percutan Tech 18:479-482

Authors do not have any financial support for the study. They have full control on all primary data. They allow the data of the journal to be reviewed if requested. 